\title{
Evaluation of quality parameters of conical profile compounds in nodes of multi-purpose machines
}

\author{
Viktor Il'inykh ${ }^{1, *}$ \\ ${ }^{1}$ Irkutsk State Transport University, 672038 Zhuravlev street, Chita Russian Federation
}

\begin{abstract}
The article presents a study of the mandrel spindle assembly for accuracy, contact stiffness and strength. The study was made on the basis of conical profile connections with an equiaxed contour. Experiments were carried out for multi-purpose machines of various layouts on the basis of the previously developed program-mathematical complex of evaluating the parameters of the shaft-sleeve coupling. The analysis of the simulation modeling results of the accuracy of the shaft (mandrel) installation in the hole of the sleeve (spindle) is carried out taking into account the error in shape, taper, the magnitude of the assembly force and the external conditional load in the spatial setting. With respect to the three coordinate axes, the possible displacements and rotations of the tool mandrels with a modified shank design are determined when they are based and secured in the spindle. In each design case, the accuracy of the relative position of the parts of the conical profile connections was compared during reusable assembly for the horizontal and vertical machine, respectively, and during the operation of the spindle-mandrel assembly under the condition of an external load. As a result of research, it was found that the layout of the machine does not significantly affect the quality parameters of the profile connection in conditions of reusable assembly. A significant effect of the error in the shape of the mating parts of the connection has been determined, which leads to an increase in maximum contact pressures till 22MPa, a displacement of the mandrel along the $\mathrm{Z}$ axis up to $25 \mu \mathrm{m}$, and a significant influence on the ultimate external load, which leads to elastic displacements of the mandrel along the $\mathrm{Y}$ axis to $2 \mu \mathrm{m}$ for tapering 1:10.
\end{abstract}

\section{Introduction}

The developed technological support for high-speed milling on CNC (computer numerical control) machines in [1] made it possible to solve the problem of manufacturing parts of profile connections of a conical shape in longitudinal section, namely: ensuring the quality of manufacturing parts of a conical profile connection with an equiaxed contour corresponding to accuracy 6-8.

Currently, research is being conducted in Russia, as well as in the developed countries of Germany and Japan, in the field of improving the technological equipment of multi-purpose CNC machines [2, 3, 4].

The works are aimed at the development and improvement of auxiliary tool designs working in automatic and manual shift conditions.

Designs of tool mandrels of the type SK, HSK, PSK, as well as DBT with shanks of a taper of 7:24 and 1:10 of a round cross-sectional shape, as well as a crosssectional profile with various fixing methods in the machine spindle are known.

The aim of this work is to assess the quality parameters of auxiliary tool designs of multi-purpose machines made on the basis of conical profile connections of normal and special taper and operated under conditions of reusable assembly-disassembly of the spindle-mandrel connection.

As it is known, an assessment of the accuracy position of the connection parts based on the reproduction of the conjugation process applied to conical connections of circular cross-section with a special and normal taper, taking into account the roughness of the parts (shaft) of the connection, assembly force and other factors, is presented in [5, 6].

\section{Materials and methods}

To predict the accuracy and stiffness of the profile conical spindle-mandrel connection, the accuracy of which is determined each time at the stage of its assembly and subsequent operation, development of software mathematics and a series of simulation experiments were required.

Subsequent statistical processing of the obtained results was carried out to determine the influence of factors, namely: assembly force, external loads and tilt angle of the cone, as well as the shape error on the accuracy of installation of assembled parts of the profile connection.

\footnotetext{
*Corresponding author: ilinykh.viktor5@mail.ru
} 
The application of computer-aided design techniques developed in [7, 8, 9] and the analysis made it possible to establish that with an assembly force of $900 \mathrm{~N}$ a more accurate mutual position of the profile connection parts with a taper of $1: 10$ is provided.

The calculations also determined that the depressions (elastic displacements) of shaped mandrels are of the same order when compared with traditional round conical connections. At the same time, the former provide guaranteed immobility of the connection parts, and therefore exclude the change of bases during the operation.

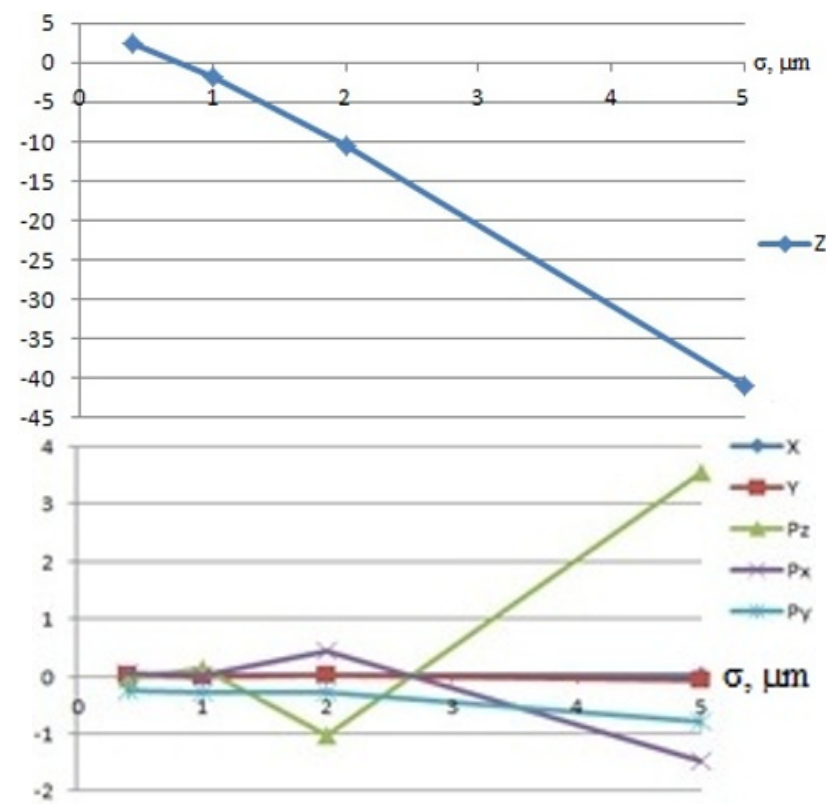

a) horizontal layout of the machine

\section{Results and Discussion}

First of all, let's analyze the influence of the layout of the machine, namely: the position of the axes of the assembled machine spindle and tool mandrel on the accuracy parameters of the conical profile connections.

The graph (Figure 1) shows the mathematical expectations of the linear $(\mathrm{X} ; \mathrm{Y} ; \mathrm{Z}, \mu \mathrm{m})$ and angular deviations $\left(\mathrm{P}_{\mathrm{z}} ; \mathrm{P}_{\mathrm{x}} ; \mathrm{P}_{\mathrm{y}}, \mu \mathrm{rad}\right)$ of the mandrel axis in the spindle bore system for a special taper of 7:24 at an assembly force of Fs $=900 \mathrm{~N}$ when modeling surface roughness (modeling parameter from 0.4 to $5 \mu \mathrm{m}$ ).

It is established that with an increase of the mandrel shape error, the displacement along the $\mathrm{Z}$ axis varies in the range from +5 to $-42 \mu \mathrm{m}$.

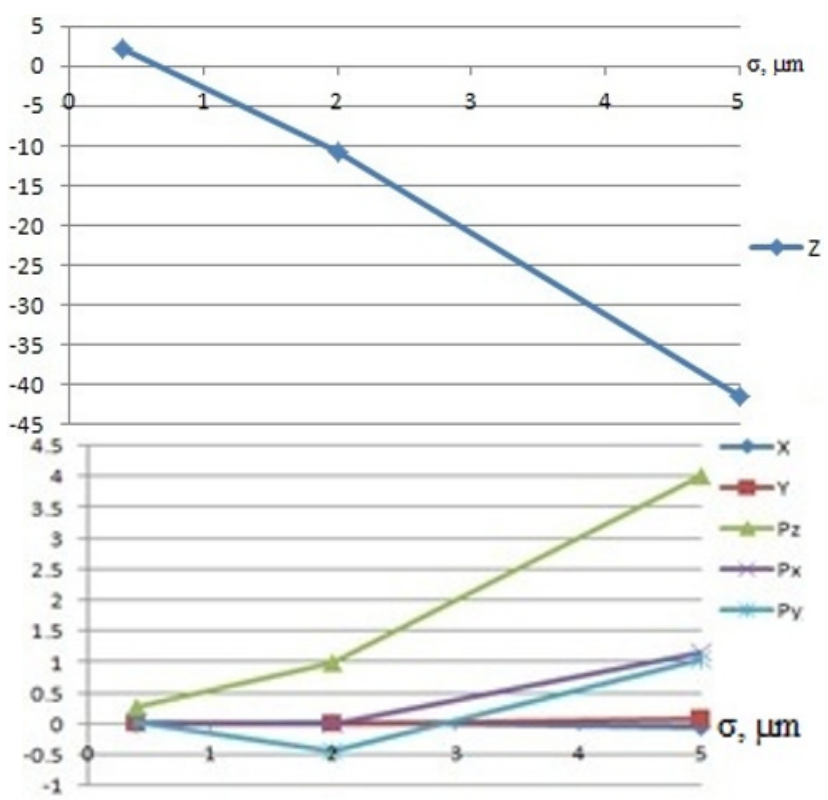

b) vertical layout of the machine

Fig.1. Mathematical expectations of linear and angular deviations of the position of the mandrel axis in the bore system from the roughness of the mandrel

The graph (Figure 2) shows the dependence of the contact parameters of the spindle-mandrel connection on the roughness of the mandrel.

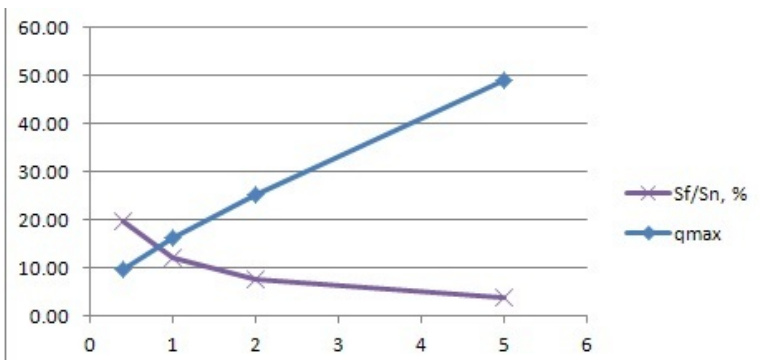

It was found that with an increase in the mandrel shape error, the maximum contact pressure increases from 10 to $50 \mathrm{MPa}$, and the relative contact area $\left(\mathrm{S}_{\mathrm{f}} / \mathrm{S}_{\mathrm{n}}\right)$ in the joint decreases by 4 times. 


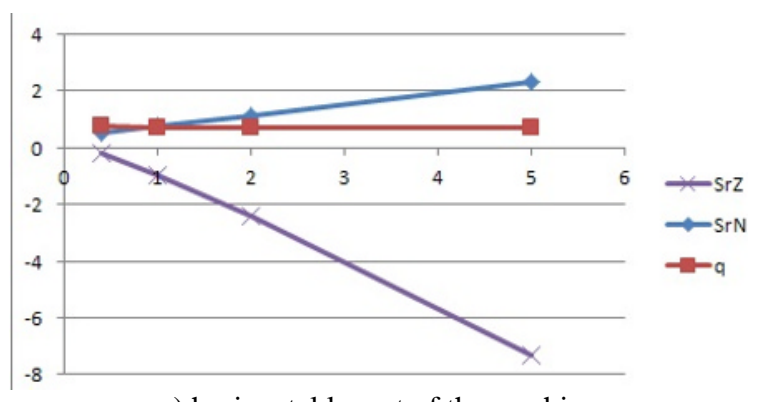

a) horizontal layout of the machine

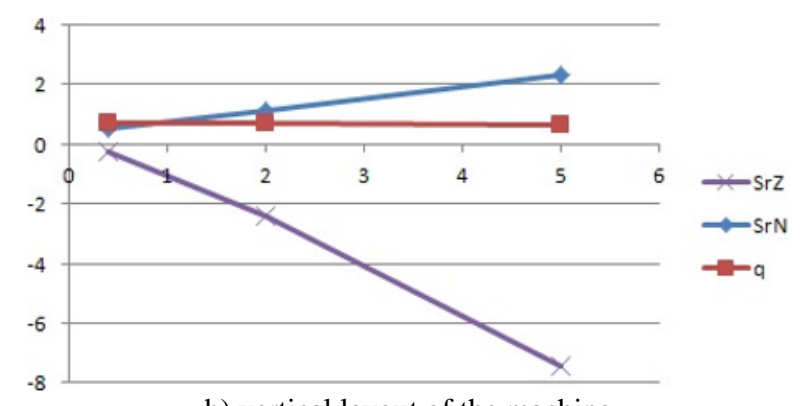

b) vertical layout of the machine

Fig.2. - Graphic dependences of the contact parameters of the spindle-mandrel connection on the roughness of the mandrel

The graph (Figure 3) shows the mathematical expectations of linear $(\mathrm{X} ; \mathrm{Y} ; \mathrm{Z}, \mu \mathrm{m})$ and angular deviations $\left(\mathrm{P}_{\mathrm{z}} ; \mathrm{P}_{\mathrm{x}} ; \mathrm{P}_{\mathrm{y}}, \mu \mathrm{rad}\right)$ of the mandrel axis in the spindle bore system for a taper of 1:10 with an assembly force of Fs $=700 \mathrm{~N}$.

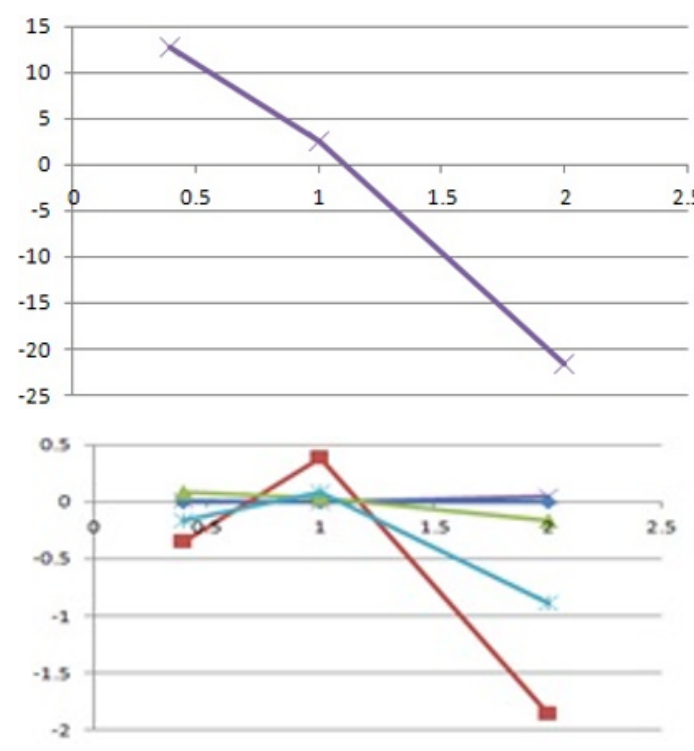

a) horizontal layout of the machine
It has been established that with an increase in the error of the mandrel shape, the displacement along the $\mathrm{Z}$ axis varies in the range from $+12,5$ to $-25 \mu \mathrm{m}$.

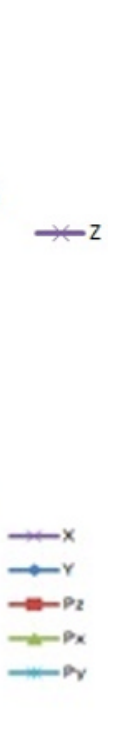

Fig. 3. Mathematical expectations of linear and angular deviations of the position of the mandrel axis in the bore system from the roughness of the mandrel.

The graph (Figure 4) shows the dependence of the contact parameters on the roughness of the mandrel.

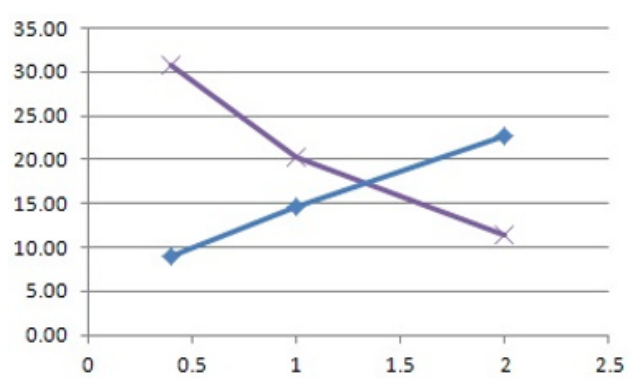

It has been established that with an increase in the error of the mandrel shape, the maximum contact pressure (qmax, MPa) increases from 9 to $22.5 \mathrm{MPa}$.

The relative contact area in the connection is reduced to 3 times.

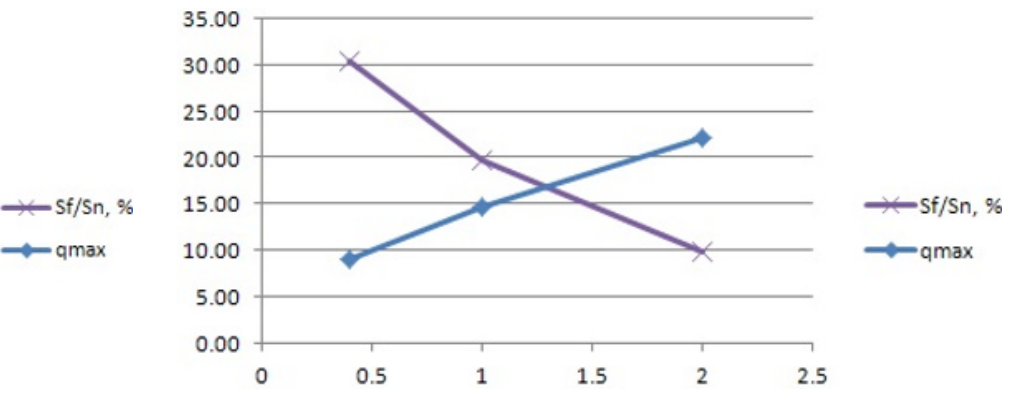




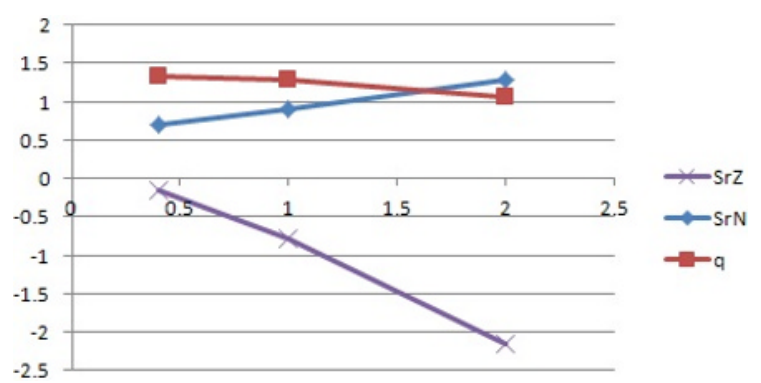

a) horizontal layout of the machine

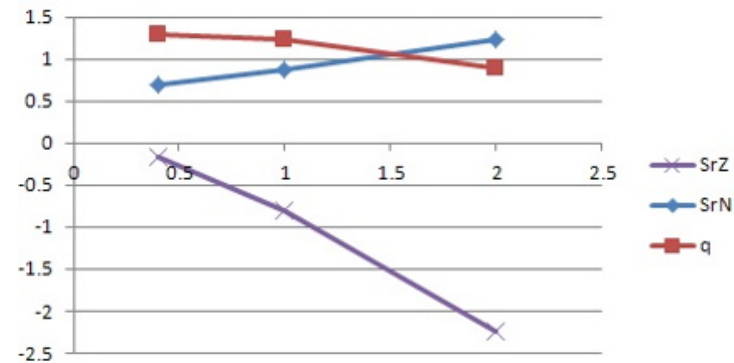

b) vertical layout of the machine

Fig.4. Graphic dependences of the contact parameters on the roughness of the mandrel

An analysis of the results obtained in the simulation of the installation process of the connection parts allows us to conclude that the layout of the machine has a slight effect on the quality parameters of conical profile spindle-mandrel connections for tapers of 7:24 and 1:10, with mandrel fixing forces from 700 to $900 \mathrm{~N}$.

Significant effect on the parameters characterizing the contact interaction of the details of the profile connection has an error in the geometric shape of the landing surface of the mandrel shank.

That is to a less extent for tapering 1:10.

It should be noted that with the mandrel taper of 7:24 and the assembly force $\mathrm{Fs}=900 \mathrm{~N}$ for the vertical layout machine, a slight change in the linear and angular accuracy parameters characterizing the position of the mandrel when simulating the installation process with operational (worn) roughness of the mandrel landing

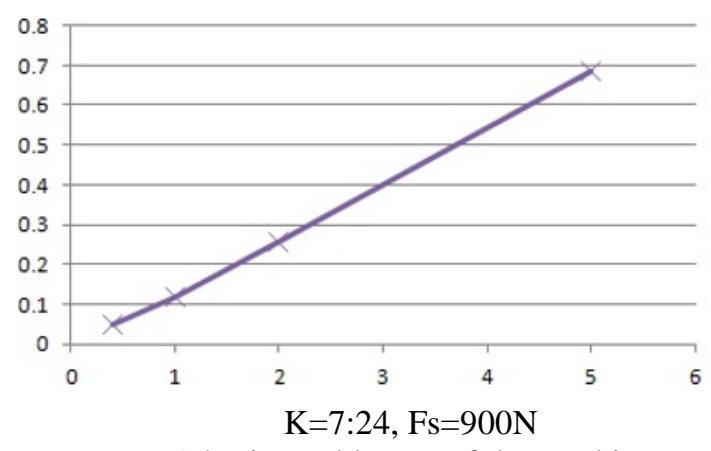

a) horizontal layout of the machine
It is of interest the analysis of the influence of the geometric shape taper of the profile connection parts on the parameters of the interface in the simulation of the assembly process of the connection.

Figure 6 shows graphical dependences of the standard deviations of the parameters characterizing the accuracy of the relative position of the details of the profile connection when basing and fixing, as well as the stiffness and strength parameters of the profile connections on the taper. surface ( $\sigma=5.0 \mu \mathrm{m}$ when modeling geometric shapes) is seen.

When simulating the installation process of a tool mandrel with a taper of 1:10 and an assembly force of Fs $=700 \mathrm{~N}$ for a horizontal layout machine, an increase in the relative contact area by 1.5 times, a decrease in the maximum contact pressure to $9 \mathrm{MPa}$, and average contact pressure (q, MPa) to $1.37 \mathrm{MPa}$ for surface roughness mandrels $(\sigma=0.4 \mu \mathrm{m}$ when modeling the shape) are noted.

A statistical assessment of the quality parameters of the connection (calculation of the standard deviation of the statistical series of numerical values of the displacements) shows that with a decrease in the mandrel shape error $\sigma$, the standard deviation of the displacement along the $\mathrm{Z}$ axis decreases and has a non-linear character (Figure 5).

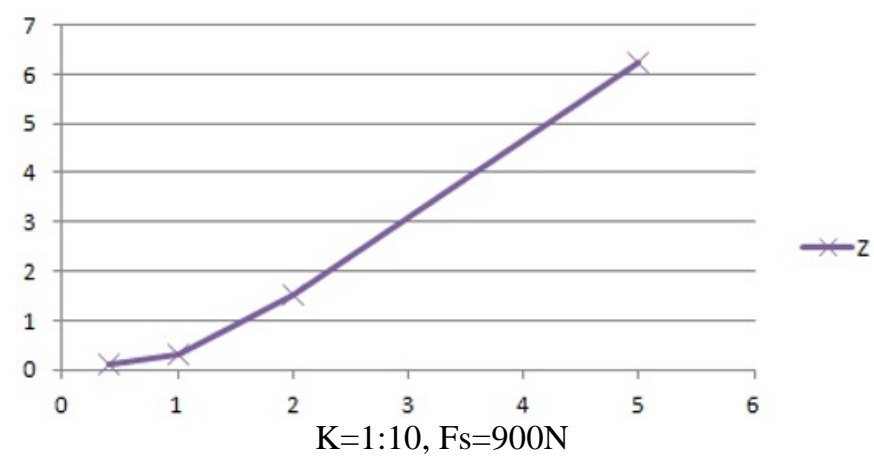

b) vertical layout of the machine

The calculations established that the scatter of linear displacements along the $\mathrm{X}$ axis with the taper of the mandrels 1:10 and 7:24 is approximately equal, and is $0.03 \mu \mathrm{m}$. The scatter of offsets along the $\mathrm{Z}$ axis for taper $1: 10$ is $0.125 \mu \mathrm{m}$, for taper $7: 24$ it is $0.03 \mu \mathrm{m}$. The spread of the angular displacements of the mandrel along the $\mathrm{Y}$ axis for a taper of $1: 10$ is $0.5 \mu \mathrm{rad}$ and a taper of $7: 24$, respectively, is $0.65 \mu \mathrm{rad}$. The spread of the angular displacements of the mandrel along the $\mathrm{X}$ axis for a taper of $1: 10$ is $0.6 \mu \mathrm{rad}$ and a taper of $7: 24$, respectively, is $0.6 \mu \mathrm{rad}$ (Figure 6-b). 


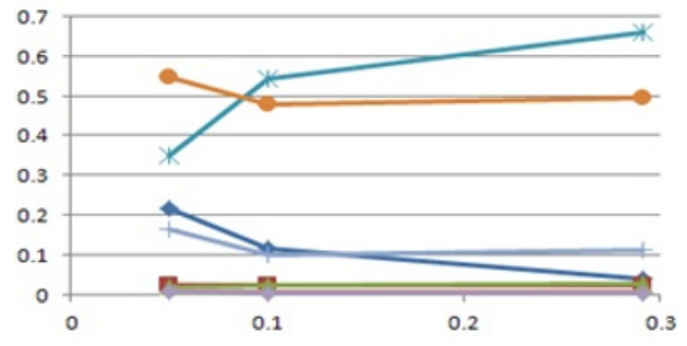

a) $\mathrm{Fs}=700 \mathrm{~N}, \sigma=0.4 \mu \mathrm{m}$

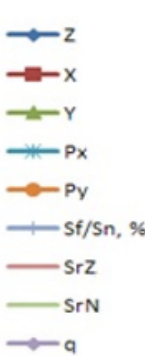

Fig.6. Influence of taper on the error in the installation of mandrels (vertical layout of the machine)

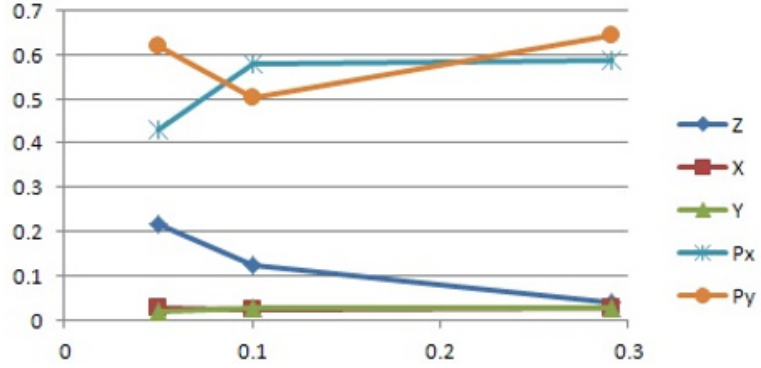

б) $\mathrm{Fs}=900 \mathrm{~N}, \sigma=0.4 \mu \mathrm{m}$

According to the results of the study of profile connections with an equiaxial contour with the number of faces equal to three for accuracy and rigidity, it was found that with idealization of the geometric shape of the mating parts of the joint, the taper $1: 10$ is most optimal $[10,11,12,13,14,15,16,17,18]$.

The influence of the assembly force Fs causes a change in the angle of rotation of the mandrel during

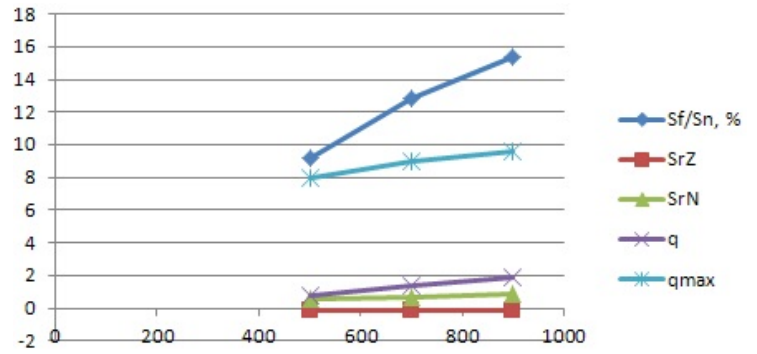

Fig.7. Effect of assembly force on the connection parameters $(K=1: 10, \sigma=0.4 \mu \mathrm{m})$

An increase in the scatter of axial angular rotations with respect to the $\mathrm{Z}(\mathrm{Pz})$ axis and the average gaps (clearances) SrZ, $\mu \mathrm{m}$ (Figure 8) for the taper of the parts of the joint 1:20 with the fastening force of the tool

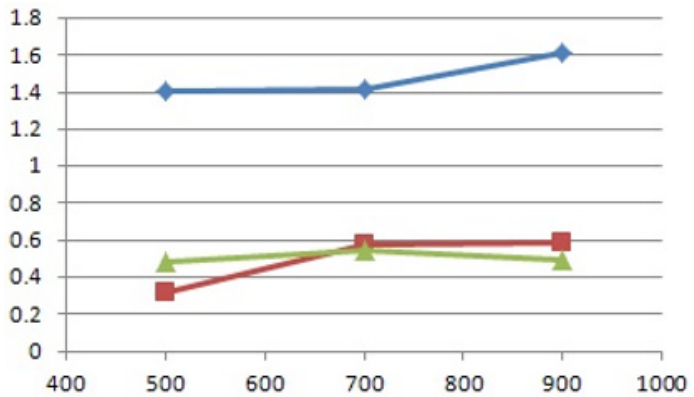

fastening, the relative contact area, the magnitude of the interference $(\mathrm{SrN}, \mu \mathrm{m})$ in the connection up to $1 \mu \mathrm{m}$, average contact pressure up to $2 \mathrm{MPa}$ and maximum contact pressure up to $10 \mathrm{MPa}$. The offset along the $\mathrm{Z}$ axis of the mandrel (Figure 7) is linear. Moreover, the layout of the machine does not affect the quality parameters of the connection.

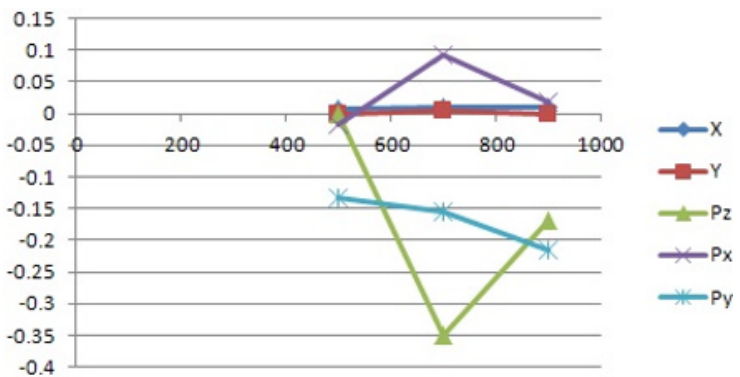

shank Fs $=900 \mathrm{~N}$ was established. This circumstance will probably affect the manufacturing accuracy of the products when fastening the cutting tool in mandrel with high tightening force.

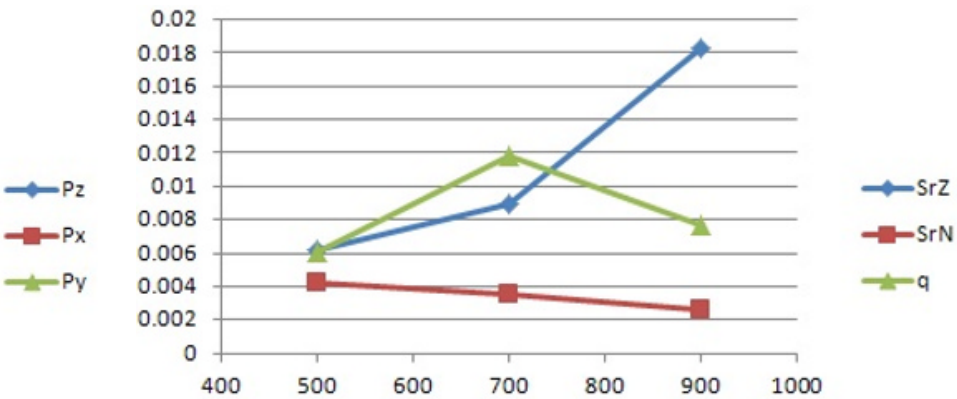

Fig.8. The effect of the tightening force of the cutting tool in the mandrel on the mating parameters (at $\mathrm{K}=1: 20, \sigma=0.4 \mu \mathrm{m}$ in the simulation)

When modeling the operation of the profile connection under the condition of an external conditional load F0, it was found that with an increase in the cutting force, the elastic squeezes (linear and angular) increase, as well as the tightness, the relative contact area and contact pressures in the connection (Fig. 9-a). At the same time, the scatter of linear and angular squeezes increases (Figure 9-b). The spread of the values of interference, average contact pressure, the relative contact area is reduced. 


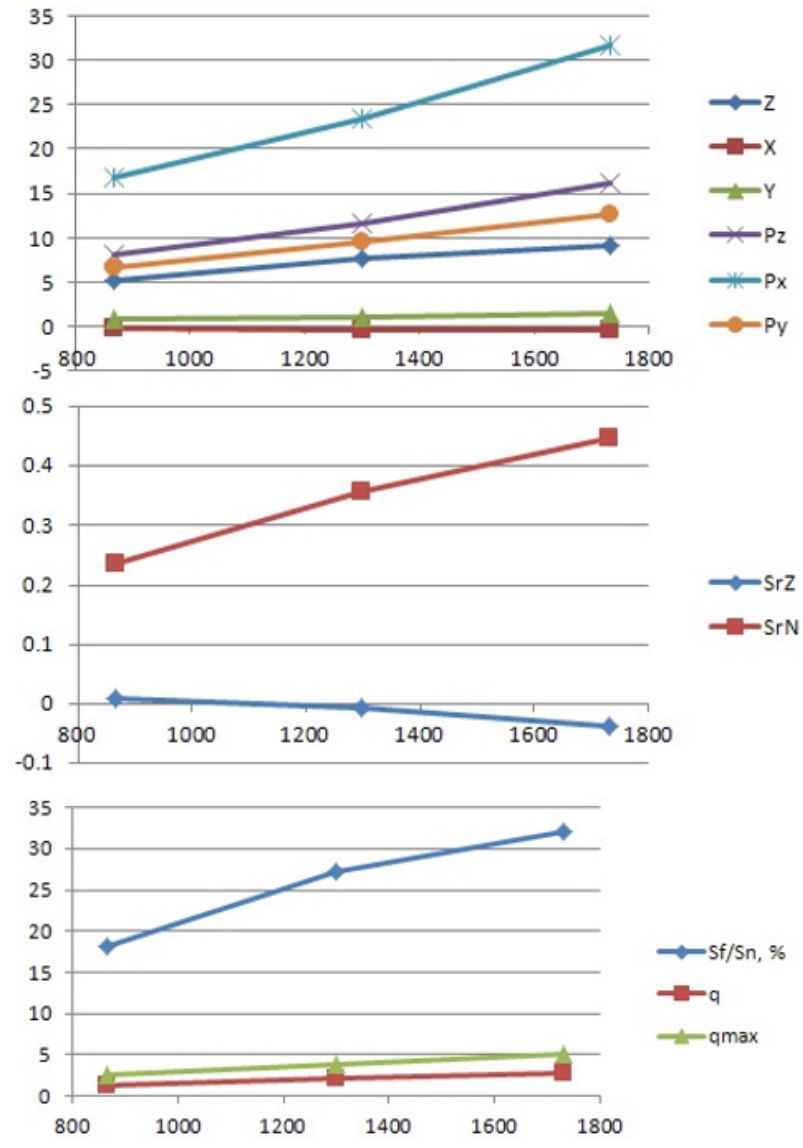

a) the value of the quality parameters

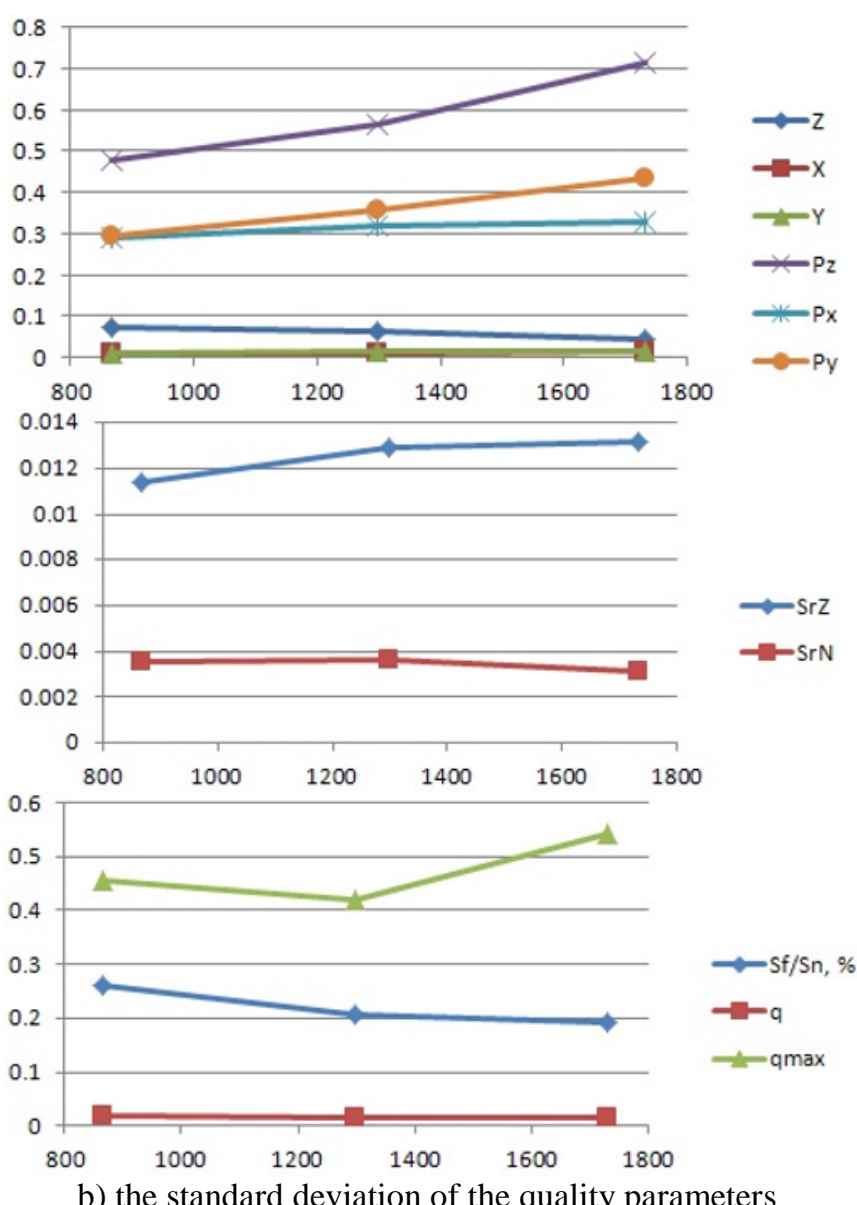

b) the standard deviation of the quality parameters

Fig.9. The influence of the conditional external load on the quality parameters of the profile connections K 1:10 assembly strength $900 \mathrm{~N}$ at $\sigma=0.4 \mu \mathrm{m}$

At the values of the maximum external load, the elastic squeezes of the mandrel do not exceed $2 \mu \mathrm{m}$, the displacement of the mandrel along the longitudinal $\mathrm{Z}$ axis is not more than $10 \mu \mathrm{m}$, the relative rotation of the mandrel along the $\mathrm{X}$ axis is not more than $32 \mu \mathrm{rad}$, and along the $\mathrm{Z}$ axis it is not more than $16.25 \mu \mathrm{rad}$.

\section{Conclusions}

1. As a result of calculations of conical profile spindle-mandrel connections, a slight effect of the machine layout on the quality parameters of conical profile connections during reusable assembly at tapers of 7:24 and 1:10 with mandrel fixing forces from 700 to $900 \mathrm{~N}$ was established.

2. The quality parameters of the conical profile connections are affected by the error of the geometrical shape of the mandrels. It was established that with an increase in the mandrel shape error, the maximum contact pressure in the connection at a taper of 1:10 increases from 9 to $22.5 \mathrm{MPa}$, and the relative contact area decreases by 3 times. The magnitude of the axial displacement of the mandrels with increasing shape error varies from +12.5 to -25 $\mu \mathrm{m}$.
3. It was found that with an increase in the clamping force to $900 \mathrm{~N}$, the angular rotations of the conical profile mandrels in the machine spindle change to $-0.2 \mu \mathrm{rad}$. The preload value in the connection increases to $1 \mu \mathrm{m}$, the average contact pressure is not more than $2 \mathrm{MPa}$ and the maximum contact pressure is not more than 10 MPa.

4. It was established that an increase in the ultimate external load up to $1800 \mathrm{~N}$ leads to elastic squeezes of the profile mandrel at the butt no more than $2 \mu \mathrm{m}$, axial movement of the mandrel to $+10 \mu \mathrm{m}$ and angular rotations no more than $32 \mu \mathrm{rad}$ with a taper of 1:10 and a shape error of $0.4 \mu \mathrm{m}$ in the simulation.

\section{References}

1. N. V. Zenin, M. S. Kamsyuk Technological methods of forming surfaces of keyless joints // Assembly in mechanical engineering instrument-making industry 9, pp. 35-40 (2005)

2. A. I. Timchenko, P-3-profile connections and their application in various industries // STIN. 2, pp. 13-18 (1993)

3. N. S. Indakov, To the study of torsional stiffness and wear resistance of profile joints Sb. Engineering technology, Tula, TPI, pp. 132-133 (1977) 
4. V. A. Il'inykh, Assessment of the influence of design parameters on the stress state of the joints of the P-3-profile compounds by polarization-optical method Bulletin of mechanical engineering, M.: Engineering 11, pp. 64-66 (1990)

5. V. Yu. Lineytsev, V. A. Il'inykh, P. Yu. Lukyanov Certificate of industry registration of computer programs. Modeling the mating of conical connection parts 5948 (2006)

6. V. Yu. Lineytsev, Contact strength, stiffness, accuracy and detachable fixed conical connections in tool systems. Thesis for the degree of candidate of technical sciences in the specialty 01.02.06 Dynamics, strength of machines, devices and equipment. Irkutsk: IrGUPS p. 217 (2006)

7. V. A. Il'inykh, Simulation modeling of details of conical connection on the basis of P-3-profile curves Modern technology. System analysis. Modeling. Scientific journal Irkutsk: IrGUPS 2(46), pp. 51-55 (2015)

8. V. A. Il'inykh, Study of conical P-3-prosile compounds for accuracy and stiffness Modern technology. System analysis. Modeling. Irkutsk: IrGUPS. 1(53) pp. 36-39 (2017)

9. V. A. Il'inykh, Spindle-tool mandrel Utility model patent: 184076, State register of utility models. Patent application for utility model 2018109190 (2018)

10 . V. A. Il'inykh, The effect of conical profile joints on the accuracy and rigidity of technological sets of multi-purpose machines Scientific and Technical Journal of SPbPU. Natural and engineering sciences, 24, 4, pp. 150-159 (2018)

11. V. A. Il'inykh, Statistical analysis of the geometry of the profile parts of the spindle assembly of multi-purpose machines Scientific and Technical Journal of SPbPU. Natural and engineering sciences, 25, 2, pp. 132-140, (2019)

12. V. A. Il'inykh, Evaluation of the accuracy and strength of the modular system of an auxiliary tool based on profile joints Bulletin of Irkutsk State Technical University, 23(3), pp. 451-462, (2019)

13. V. A. Il'inykh, Calculation of the stress-strain state of the hub with P-3-profile hole. Modern technology. System analysis. Modeling. Scientific journal 3(27), Irkutsk: IrGUPS pp. 69-73 (2010)

14. V. A. Il'inykh, The calculation of the strength of the P-3-profile of preloaded joints Modern technology. System analysis. Modeling. Scientific journal 2(34) Irkutsk: IrGUPS pp. 17-20, (2012)

15. Ye. A. Rozhkova, V. A. Il'inykh, V. Yu. Lineytsev, Profile connection shaft-hub with equilibrium contour with tension Utility model patent: 142049, State register of utility models. Patent application for utility model 2013149425 (2013)

16. Ye. A. Rozhkova, V. A. Il'inykh, V. Yu. Lineytsev, Modified profile moments transmitting connection shaft-hub with equilibrium contour with tension Utility model patent: 155119, State register of utility models. Patent application for utility model 2015107771 (012545) (2015)
17. E. A. Rozhkova, Modified tool mandrel multipurpose machine / E. A. Rozhkova, V. E. Yarilov / utility model Patent No. 190690 (2019)

18. N. A. Pshenichnikova, Application of the method of cumulative sums in assessing the error of the shape of profile shafts. Scientific and technical Bulletin of the Volga region - Kazan LLC "Scientific and technical Bulletin of the Volga region" 1, pp. 126-128 (2019) 